\title{
A Survey to Define and Predict Difficult Vascular Access in the Pediatric Perioperative Population
}

This article was published in the following Dove Press journal:

Pediatric Health, Medicine and Therapeutics

\author{
Mohammed Hakim' \\ Shabana Zainab Shafy' \\ Joshua C Uffman (1D ${ }^{1,2}$ \\ Julie Rice' \\ Vidya T Raman (D) ${ }^{1,2}$ \\ Joseph D Tobias $\mathbb{D}^{1,2}$ \\ Ralph J Beltran (D) ${ }^{1,2}$
}

'Department of Anesthesiology and Pain Medicine, Nationwide Children's Hospital, Columbus, OH, USA;

${ }^{2}$ Department of Anesthesiology and Pain Medicine, The Ohio State University

College of Medicine, Columbus,

$\mathrm{OH}$, USA
Correspondence: Mohammed Hakim Department of Anesthesiology and Pain Medicine, Nationwide Children's Hospital, 700 Children's Drive, Columbus, $\mathrm{OH}$ 43205, USA

Tel + I 614 680-2552

$\mathrm{Fax}+1$ 614 722-4203

Email mushtaqahmedhakim.2@osu.edu
Background: Various criteria exist for defining difficult peripheral intravenous (DPIV) cannulation in infants and children. With the help of a survey tool, the characteristics perceived to increase the likelihood of DPIV cannulation amongst anesthesia providers were assessed.

Methods: An individualized survey regarding DPIV which included pediatric anesthesiology faculty and certified registered nurse anesthetists at Nationwide Children's Hospital and anesthesiology faculty members of Wake-up Safe was conducted. Anesthesia provider, patient, and procedural characteristics were expressed as a count and percentage, and compared according to group (faculty, certified registered nurse anesthetists, Wake-up Safe faculty) using analysis of variance.

Results: Of the 48 local respondents, $33(69 \%)$ reported age as a contributing factor to DPIV, and $32(67 \%)$ reported weight as a factor. Of the 22 Wake-up Safe respondents, 14 $(63 \%)$ reported age, and $16(73 \%)$ reported weight as a factor. Patient and procedural characteristics perceived to increased likelihood of DPIV cannulation did not differ by respondent role. The factors most commonly mentioned by local respondents as contributing to DPIV included trisomy 21, neuromuscular disorders, and history of many prior IV cannulations. Among the Wake-up Safe faculty respondents, the most commonly mentioned factors were neuromuscular disorders, trisomy 21, and skin injuries or conditions.

Conclusion: Age and weight were the two most commonly reported factors from both groups of respondents. Other factors contributing to DPIV included prior history of DPIV, neuromuscular disorders, trisomy 21 and American Society of Anesthesiology status $\geq 4$. Patient and procedural characteristics were perceived to increase the likelihood of DPIV cannulation with no difference among respondents.

Keywords: peripheral intravenous cannulation, pediatric anesthesiology, difficult peripheral intravenous cannulation

\section{Introduction}

The insertion of a peripheral intravenous (IV) cannula is the most common invasive procedure performed in health care settings. ${ }^{1}$ Intravenous cannulation is vital to allow for the administration of fluid, medications, contrast agents for imaging, and transfusion of blood and blood products. In all except the simplest and briefest of surgical procedures, placement of a peripheral intravenous cannula is performed following the induction of anesthesia, and prior to the start of the surgical procedure. ${ }^{2}$ Nonetheless, obtaining IV access may be challenging even for experienced health-care professionals. ${ }^{3}$ In fact, placement of a peripheral intravenous cannula may be one of the more common challenges faced during the provision of anesthesia to infants and children. ${ }^{4,5}$ 
In pediatric anesthesia, there are various definitions as to what constitutes difficult placement of an intravenous (DPIV) cannula, and what type of patients or clinical circumstances are particularly challenging. In addition, providers may have various levels of experience as well as expertise with alternative methods for cannulation, such as ultrasound (US) guidance, vein finders, infrared devices, and other adjunctive aids. ${ }^{6,7}$ A survey of anesthesia providers at our institution and participating Wake-up Safe (WUS) member faculty was conducted to determine what factors the practitioners felt contributed to DPIV. WUS is a certified patient safety organization that contains a registry of serious adverse events (AEs) reported on a voluntary basis by participating institutions.

\section{Methods}

This study was reviewed and approved by the Institutional Review Board of Nationwide Children's Hospital. As a survey study without the involvement of human subjects, a waiver of informed consent and HIPAA authorization was granted. The individualized survey for the study which is outlined in Table 1 was distributed via email to anesthesia providers including pediatric anesthesiology faculty and certified registered nurse anesthetists (CRNA) at Nationwide Children's Hospital (NCH), and anesthesiology faculty members of WUS. WUS is a patient safety organization established in 2008 by the Quality and Safety Committee of the Society for Pediatric Anesthesia that maintains a registry of de-identified, serious AEs associated with children receiving anesthetic care.

The demographic information collected on anesthesia provider characteristics included years in clinical practice, training and experience in US-guided venous cannulation, and number of unsuccessful venous cannulation attempts they would make prior to calling for assistance or using US guidance. Data on patient and procedure characteristics perceived to increase the likelihood of DPIV cannulation including patient age, weight, American Society of Anesthesiologists' (ASA) physical status, and procedure/surgery type was also collected. Respondents also described patient factors contributing to DPIV in free-response fields. The respondents were asked to choose one option for each of the questions listed in the table. Anesthesia provider, patient, and procedural characteristics were expressed as a count and percentage, and compared according to group (faculty, CRNA, WUS) using ANOVA. All statistical analyses
Table I Survey on Factors that Affect Difficult Peripheral Intravenous Cannulation

\begin{tabular}{|c|c|}
\hline Variables & $\begin{array}{l}\text { Choose One of the } \\
\text { Following }\end{array}$ \\
\hline Patient's age & $\begin{array}{l}\text { - Prematurity }(<37 \text { weeks } \\
\text { estimated gestational age) } \\
\text { - Newborn (<1 month } \\
\text { since birth) } \\
\text { - }>1 \text { to } 6 \text { months } \\
\text { - }>6 \text { months to } 12 \text { months } \\
\text { - >12 months to } 3 \text { years } \\
\text { - >3 years to } 5 \text { years } \\
\text { - }>5 \text { years, but }<10 \text { years } \\
\text { - }>10 \text { years, but }<15 \text { years } \\
\text { - }>15 \text { years }\end{array}$ \\
\hline $\begin{array}{l}\text { State the patient's weight if they are } \\
\text { premature, newborn, or under two years } \\
\text { of age }\end{array}$ & $\begin{array}{ll}- & \leq 1 \mathrm{~kg} \\
- & >1-2 \mathrm{~kg} \\
- & >2-3 \mathrm{~kg} \\
- & >3-4 \mathrm{~kg} \\
- & >4-6 \mathrm{~kg} \\
- & \text { Inapplicable; patient is } \geq 2 \\
& \text { years of age }\end{array}$ \\
\hline $\begin{array}{l}\text { For patients two years or older, provide } \\
\text { their body mass index (BMI) adjusted as } \\
\text { a percentile for age }\end{array}$ & $\begin{array}{ll}\text { - } & <50 \% \\
\text { - } & 51-75 \% \\
\text { - } & >76-95 \% \\
\text { - } & 96-98 \% \\
\text { - } & >99 \%\end{array}$ \\
\hline Patient's gender & $\begin{array}{l}\text { - } \text { Male } \\
\text { - Female }\end{array}$ \\
\hline Patient's race* & $\begin{array}{l}\text { - American Indian or } \\
\text { - Alaska Native } \\
\text { - } \text { Asian } \\
\text { - Hispanic or Latino } \\
\text { - Native Hawaiian or other } \\
\text { Pacific Islander } \\
\text { - White or Caucasian } \\
\text { - Not sure/not applicable }\end{array}$ \\
\hline Patient's ethnicity* & $\begin{array}{l}\text { - Hispanic } \\
\text { - Non-Hispanic } \\
\text { - Not sure/not applicable }\end{array}$ \\
\hline $\begin{array}{l}\text { Other patient characteristics. Check all } \\
\text { that apply. }\end{array}$ & $\begin{array}{l}\text { - Trisomy } 2 \mathrm{I} \\
\text { - History of neuromuscu- } \\
\text { lar condition } \\
\text { - History of congenital } \\
\text { heart disease } \\
\text { - History of joint or limb } \\
\text { condition } \\
\text { - History of skin condition } \\
\text { - History of multiple or } \\
\text { recent cannulations }\end{array}$ \\
\hline
\end{tabular}

(Continued) 
Table I (Continued).

\begin{tabular}{|c|c|}
\hline Variables & $\begin{array}{l}\text { Choose One of the } \\
\text { Following }\end{array}$ \\
\hline Patient's associated syndromes & - Describe, if any \\
\hline $\begin{array}{l}\text { What other characteristics of the patient } \\
\text { or case contributed to difficulty with IV } \\
\text { access? }\end{array}$ & - Describe, if any \\
\hline Variable & $\begin{array}{l}\text { Choose one of the } \\
\text { following }\end{array}$ \\
\hline $\begin{array}{l}\text { Please select the type of surgery or field } \\
\text { performed intra-abdominal or pelvic } \\
\text { surgery during this encounter. }\end{array}$ & $\begin{array}{l}\text { - Intra-abdominal or pelvic } \\
\text { surgery } \\
\text { - Orthopedic } \\
\text { - Neurologic } \\
\text { - Plastics } \\
\text { - Other surgical specialty/ } \\
\text { - } \text { Imacedure } \\
\text { anesthesia }\end{array}$ \\
\hline $\begin{array}{l}\text { Please identify your role as anesthesia } \\
\text { provider }\end{array}$ & $\begin{array}{l}\text { - Attending physician } \\
\text { - } \text { CRNA } \\
\text { - Resident in anesthesiology } \\
\text { - Resident, other specialty } \\
\text { - Fellow in pediatric } \\
\text { anesthesiology } \\
\text { - Fellow, other specialty } \\
\text { - Student nurse anesthetist } \\
\text { (SRNA) }\end{array}$ \\
\hline $\begin{array}{l}\text { Clinical experience in your current role } \\
\text { (years in practice)? }\end{array}$ & $\begin{array}{l}\text { - } 0-5 \text { years } \\
\text { - } 6-10 \text { years } \\
\text { - } 11-15 \text { years } \\
\text { - }>15 \text { years }\end{array}$ \\
\hline $\begin{array}{l}\text { Select the best option that describes your } \\
\text { training in anesthesiology }\end{array}$ & $\begin{array}{l}\text { - } 0-5 \text { years } \\
\text { - } 6-10 \text { years } \\
\text { - } 11-15 \text { years } \\
\text { - }>15 \text { years }\end{array}$ \\
\hline $\begin{array}{l}\text { Regarding US use, how did you acquire } \\
\text { your clinical experience? Please select } \\
\text { one option. }\end{array}$ & $\begin{array}{l}\text { - Residency/Fellowship } \\
\text { academic training } \\
\text { - US-guided vascular } \\
\text { access workshop } \\
\text { - On-the-job training with } \\
\text { expert assistance } \\
\text { - Self-taught } \\
\text { - I have no experience with } \\
\text { this technology }\end{array}$ \\
\hline $\begin{array}{l}\text { How many unsuccessful venous } \\
\text { cannulation attempts would you make } \\
\text { prior to calling for assistance? }\end{array}$ & $\begin{array}{ll}\text { - } & 0-5 \\
\text { - } & 6-10 \\
\text { - } & 11-15 \\
\text { - } & 16-20 \\
\text { - } & >20 \\
\text { - } & \text { Not sure/not applicable }\end{array}$ \\
\hline
\end{tabular}

(Continued)
Table I (Continued).

\begin{tabular}{|l|l|}
\hline Variables & $\begin{array}{l}\text { Choose One of the } \\
\text { Following }\end{array}$ \\
\hline $\begin{array}{l}\text { Are you aware of NCH Department of } \\
\begin{array}{l}\text { Anesthesia and Pain Management } \\
\text { guidelines for number of cannulation } \\
\text { attempts prior to calling for assistance? }\end{array}\end{array}$ & \begin{tabular}{l}
$\bullet$ Yes \\
\hline
\end{tabular}
\end{tabular}

Note: *Race and Ethnicity as defined by "Standards for the classification of Federal Data on Race and Ethnicity," provided by Executive Office of the President, Office of Management and Budget (OMB), Office of Information and Regulatory Affairs.

were completed using SAS 9.4 (SAS Institute, Cary, NC, USA).

\section{Results}

Responses were obtained from $62 \%$ of local faculty $(\mathrm{n}=25), 56 \%$ of local CRNAs $(\mathrm{n}=23)$, and $21 \%$ of WUS member faculty $(\mathrm{n}=22)$. Anesthesia provider characteristics according to group are summarized in Table 2. Of the 48 local respondents, $42(88 \%)$ stated they would call for assistance or use US after fewer than five unsuccessful IV attempts. Of the 22 WUS respondents, 17 (77\%) stated they would call for help or use US guidance after fewer than five unsuccessful attempts, and four (18\%) would call for help or use US guidance after 6-10 unsuccessful attempts. Among the 42 local providers and 20 WUS members with US experience, 16 local providers $(38 \%)$ and 10 WUS members $(50 \%)$ had received formal training in US, while 25 locals $(62 \%)$ and 10 WUS members $(50 \%)$ reported learning US "on-the-job". The remaining eight providers reported no experience with US guidance. Experience with US guidance did not differ according to study group $(p=0.572$ ). Local CRNAs generally had less experience than local faculty or WUS member faculty with US guidance $(p<0.01)$.

Patient and procedural characteristics which were felt to contribute to DPIV cannulation are summarized in Table 3. Of the 48 local respondents, 33 (69\%) reported age as a factor contributing to DPIV and $32(67 \%)$ reported weight as a factor. Of the 22 WUS respondents, $14(63 \%)$ reported age as a factor and $16(73 \%)$ reported weight as a factor. With respect to the patient's race and ethnicity, amongst the local respondents, 32 (52\%) reported black or African American race to contribute to DPIV cannulation; and $28(45 \%)$ did not choose an applicable answer choice from the listed options. WUS respondents reported similar results, with $12(60 \%)$ reporting Black or African 
Table 2 Counts and Percentages of Provider Characteristics by Role of Anesthesia Provider, n (\%)

\begin{tabular}{|c|c|c|c|c|}
\hline Measure $^{\mathrm{a}}$ & $\begin{array}{l}\text { Faculty } \\
(\mathbf{n}=\mathbf{2 5})\end{array}$ & $\begin{array}{l}\text { CRNA } \\
(n=23)\end{array}$ & $\begin{array}{l}\text { WUS } \\
(n=22)\end{array}$ & $p$-value \\
\hline \multicolumn{5}{|c|}{$\begin{array}{l}\text { Number of unsuccessful attempts before calling for assistance or using US } \\
\text { guidance }\end{array}$} \\
\hline $0-5$ & $22(95.7)$ & $20(95.2)$ & $17(77.3)$ & 0.417 \\
\hline $6-10$ & 0 & I (4.76) & $4(18.2)$ & \\
\hline$>11$ & I (4.35) & 0 & $0(0)$ & \\
\hline \multicolumn{5}{|l|}{ Years of experience } \\
\hline $0-5$ years & $7(28.0)$ & $13(56.5)$ & $4(18.2)$ & 0.001 \\
\hline $6-10$ years & $4(16.0)$ & $8(34.8)$ & $7(31.8)$ & \\
\hline$\geq 1 \mathrm{I}$ years & $14(56.0)$ & $2(8.70)$ & II (50.0) & \\
\hline \multicolumn{5}{|l|}{ US guidance skill acquisition } \\
\hline No formal experience with US guidance & $3(12.0)$ & $3(13.0)$ & $2(9.09)$ & 0.572 \\
\hline Formal training (academic training or workshop) & $7(28.0)$ & $9(39.1)$ & $10(45.5)$ & \\
\hline On-the-job training or self-taught & $15(60.0)$ & II (47.8) & $10(45.5)$ & \\
\hline
\end{tabular}

Notes: ${ }^{a}$ Totals may not sum to group size because of missing data or omitted responses. ${ }^{b} p$-value for difference across the three groups using analysis of variance. Abbreviations: ASA, American Society of Anesthesiologists; CRNA, Certified Registered Nurse Anesthetist; PIV, peripheral intravenous; US, ultrasound.

Table 3 Counts and Percentages of Patient and Procedural Characteristics by Role of Anesthesia Provider, $\mathrm{n}$ (\%)

\begin{tabular}{|c|c|c|c|c|}
\hline Measure $^{\mathrm{a}}$ & Faculty $(n=25)$ & CRNA (n=23) & WUS (n=22) & $p$-value \\
\hline \multicolumn{5}{|c|}{ Patient characteristics perceived to increase likelihood of difficult PIV cannulation } \\
\hline \multicolumn{5}{|l|}{ Patient age ${ }^{c}$} \\
\hline Premature birth (<37 weeks gestation) & $6(24.0)$ & $12(52.2)$ & $6(27.0)$ & 0.209 \\
\hline Newborn to 12 months & $9(36.0)$ & $6(26.1)$ & $8(36.4)$ & \\
\hline Age is not a factor & $9(36.0)$ & $4(17.4)$ & $5(22.7)$ & \\
\hline \multicolumn{5}{|l|}{ Patient weight } \\
\hline$<1 \mathrm{~kg}$ & $9(36.0)$ & $10(43.5)$ & $8(36.4)$ & 0.237 \\
\hline $\mathrm{I}-6 \mathrm{~kg}$ & $4(16.0)$ & $9(39.1)$ & $8(36.4)$ & \\
\hline Weight is not a factor & $12(48.0)$ & $4(17.4)$ & $4(18.2)$ & \\
\hline \multicolumn{5}{|l|}{ Patient ASA status } \\
\hline $1-3$ & $8(32.0)$ & $4(17.4)$ & $9(45.0)$ & 0.229 \\
\hline$\geq 4$ & $12(48.0)$ & II (47.8) & $6(30.0)$ & \\
\hline Any ASA number with emergency status & $5(20.0)$ & $8(34.8)$ & $5(25.0)$ & \\
\hline \multicolumn{5}{|c|}{ Procedure characteristics perceived to increase likelihood of difficult PIV cannulation } \\
\hline \multicolumn{5}{|l|}{ Procedure type } \\
\hline Surgery & $16(64.0)$ & $16(69.6)$ & $13(65.0)$ & 0.824 \\
\hline Imaging or off-site anesthesia & $7(28.0)$ & $6(26.1)$ & $7(31.8)$ & \\
\hline All of my IV placements are easy/I have not encountered a difficult IV yet & $2(8.0)$ & I (4.35) & 0 & \\
\hline
\end{tabular}

Notes: aTotals may not sum to group size because of missing data or omitted responses. ${ }^{b} p$-value for difference across the three groups using ANOVA. ${ }^{\mathrm{c}}$ Responses for "I-3 years", "> 10 and $<15$ years" excluded from comparison $(n=3)$.

Abbreviations: ASA, American Society of Anesthesiologists; CRNA, Certified Registered Nurse Anesthetist; PIV, peripheral intravenous.

American race as a contributing factor and six (30\%) not choosing an applicable choice. 56 (91\%) of local respondents and $16(80 \%)$ reported patient's ethnicity was not a contributing factor to determine DPIV cannulation. Patient and procedural characteristics perceived to increased likelihood of DPIV cannulation did not differ by respondent role. The factors most commonly mentioned by local respondents as contributing to DPIV included trisomy 21, neuromuscular disorders, and history of many prior IV cannulations. Among WUS respondents, 
the most commonly mentioned factors were neuromuscular disorders, trisomy 21 , and skin injuries or conditions.

\section{Discussion}

Intravenous cannulation is a routine procedure performed in pediatric hospitals to administer fluids and medications. DPIV cannulation poses a challenging scenario health-care professionals may face in a variety of clinical settings and situations. Problems with venous cannulation can potentially lead to delays in the induction of anesthesia, performance of diagnostic procedures, resuscitation measures, and patient management. Furthermore, the additional time consumed in the operating room can potentially delay subsequent cases and increase health-care costs. ${ }^{8}$ Multiple punctures can increase the incidence of complications including skin bruising, phlebitis, extravasation, or nerve damage, and increased needle phobia. ${ }^{9-11}$ Our clinical experience also suggests it may be a factor in patient and family dissatisfaction, as we have had experiences with parents expressing significant concern over observed puncture sites postprocedure.

Successful venipuncture with a short procedure time and limited number of attempts may be integral in achieving high patient satisfaction and creating a positive perception of the overall care experience. Early detection of the patient at risk for DPIV is necessary to allow the healthcare provider to discuss the potential for DPIV cannulation prior to anesthetic induction, to choose alternate routes or to adopt and implement strategies to increase the probability of success such as use of US guidance. ${ }^{3}$ Although widely believed that certain patient characteristics, such as high BMI or younger age may increase the incidence of DPIV cannulation, there is a paucity of literature on specific predictive factors for DPIV cannulation in pediatric patients. To help predict which children will be at risk of DPIV, Yen et al developed a scoring tool, called the Difficult Intravenous Access (DIVA) score, using key factors, including degree of palpability and visibility of the veins, history of prematurity, and age of the child. This was a prospective cohort study consisting of 615 children aged 0 to 21 years undergoing intravenous placement by staff nurses in a pediatric emergency department. Yen found that intravenous access on first attempt was achieved in $75 \%$ of the children, whereas the probability of success on first attempt was less than $50 \%$ in children with a composite DIVA score $\geq 4$. $^{5}$ Frey et al conducted a study in a tertiary pediatric institution and reported a 44\% success rate per stick with PIV placement, and an average procedure time of $20 \mathrm{~min}$ (range: 2-90 $\mathrm{min}$ ) per patient. A similar study indicated a $53 \%$ success rate of PIV placement on the first attempt with a $91 \%$ success rate within four attempts. ${ }^{12,13}$ These studies, as well as the information from the current study, may provide concepts for future quality improvement projects in this area. Moving forward, quality improvement projects aimed to limit the number of attempts or time required to achieve peripheral venous cannulation may include better identification of the number of attempts that should be allowed prior to use of US guidance. Furthermore, we are currently conducting a prospective evaluation in a large cohort of patients to more clearly define patient and provider characteristics associated with DPIV.

One of the more recent changes in practice which may decrease the incidence of DPIV cannulation is the practice of not only allowing, but actually encouraging oral preoperative hydration. Avoidance of dehydration prior to the operating room setting is feasible by the recent reevaluation of nil per os guidelines, actively encouraging clear liquids up to two hours before a procedure. In addition, improved training and education of unit personnel, institution of IV teams, and interventions to reduce pain and anxiety among patients and parents may facilitate the success of IV cannulation. ${ }^{14}$

For the current survey, the respondent group included local faculty and CRNAs from Nationwide Children's Hospital as well as WUS faculty members from institutions across the United States. With regard to provider characteristics, the majority of providers in all groups stated they would call for assistance or use US guidance before five unsuccessful attempts. One limitation of the study is that we did not differentiate regarding the number of attempts in the 0-5 range. Outside of the operating room, it is not uncommon for attempts by a single provider to be limited to two attempts. However, these practices are not universally accepted in the operating room setting as there are frequently two anesthesia providers in a single operating room (MD anesthesia faculty and CRNA, fellow or resident) as well as ready access to additional providers who are covering adjacent operating rooms. As such, the number of attempts was grouped as $0-5$.

Patient and procedural characteristics perceived to increase the likelihood of DPIV cannulation did not differ by respondent role and included both young age and high weight. The factors most commonly mentioned by local respondents as contributing to DPIV included trisomy 21, neuromuscular disorders, and history of many prior IV 
cannulations. Amongst WUS respondents, the most commonly mentioned factors were neuromuscular disorders, trisomy 21, and skin injuries or conditions. In our institution, when a DPIV scenario has been identified and peripheral venous cannulation has failed despite several attempts, additional expertise can be readily summoned. This includes anesthesia providers with specialized expertise in US guidance for establishing IV access.

The data obtained via this survey provides characteristics of what may constitute DPIV cannulation during the perioperative period, but it is subject to limitations. This tool was initially designed and tested solely on anesthesia providers in a pediatric institution. Therefore, the findings of this survey may not be generalizable to providers or caregivers from other pediatric specialties or clinical environments. With that caveat in mind, this study supports findings from previous reports confirming that there is no single patient characteristic which may predict DPIV cannulation. ${ }^{8,15}$ Respondents all opined that age, weight, and ASA physical status were important contributors. Additional research studies are warranted to provide more insight on specific factors that may lead to DPIV cannulation.

\section{Ethics}

This study was reviewed and approved by the ethics committee, named the Institutional Review Board at the Nationwide Children's Hospital and the need for informed consent was waived.

\section{Funding}

The authors have indicated they have no financial relationships relevant to this article to disclose.

\section{Disclosure}

The authors report no conflicts of interest for this work.

\section{References}

1. Wells S. Venous access in oncology and haematology patients: part one. Nurs Stand. 2008;22:39. doi:10.7748/ns2008.09.22.52.39.c6649
2. Haupert MS, Pascual C, Mohan A, Bartecka-Skrzypek B, Zestos MM. Parental satisfaction with anesthesia without intravenous access for myringotomy. Arch Otolaryngol Head Neck Surg. 2004;130:1025-1028. doi:10.1001/archotol.130.9.1025

3. Walsh G. Difficult peripheral venous access: recognizing and managing the patient at risk. $J$ Am Vasc Assoc. 2008;13:198-203. doi:10.2309/java.13-4-7

4. Riker MW, Kennedy C, Winfrey BS, Yen K, Dowd MD. Validation and refinement of the difficult intravenous access score: a clinical prediction rule for identifying children with difficult intravenous access. Acad Emerg Med. 2011;18:1129-1134. doi:10.1111/j.15532712.2011.01205.x

5. Yen K, Riegert A, Gorelick MH. Derivation of the DIVA score: a clinical prediction rule for the identification of children with difficult intravenous access. Pediatr Emerg Care. 2008;24:143-147. doi:10.1097/PEC.0b013e3181666f32

6. Benkhadra M, Collignon M, Fournel I, et al. Ultrasound guidance allows faster peripheral IV cannulation in children under 3 years of age with difficult venous access: a prospective randomized study. Pediatr Anesth. 2012;22:449-454. doi:10.1111/j.1460-9592.2012. 03830.x

7. De Graaff JC, Cuper NJ, Mungra RA, Vlaardingerbroek K, Numan SC, Kalkman CJ. Near-infrared light to aid peripheral intravenous cannulation in children: a cluster randomised clinical trial of three devices. Anaesthesia. 2013;68:835-845. doi:10.1111/anae.12 294

8. Cuper NJ, de Graaff JC, van Dijk AT, Verdaasdonk RM, van der Werff DB, Kalkman CJ. Predictive factors for difficult intravenous cannulation in pediatric patients at a tertiary pediatric hospital. Pediatr Anesth. 2012;22:223-229. doi:10.1111/j.1460-9592.2011.03 685. $\mathrm{x}$

9. Fein JA, Zempsky WT, Cravero JP; Committee on Pediatric Emergency Medicine. Relief of pain and anxiety in pediatric patients in emergency medical systems. Pediatrics. 2012;130:e1391-e1405. doi:10.1542/peds.2012-2536

10. Tsukuda Y, Funakoshi T, Nasuhara Y, Nagano Y, Shimizu C, Iwasaki $\mathrm{N}$. Venipuncture nerve injuries in the upper extremity from more than 1 million procedures. J Patient Saf. 2019;15:299-301. doi:10.1097/PTS.0000000000000264

11. Burkhardt T, Dimanski B, Karl R, et al. Donor vigilance data of a blood transfusion service: a multicenter analysis. Transfus Apher Sci. 2015;53:180-184. doi:10.1016/j.transci.2015.03.014

12. Frey AM. Success rates for peripheral IV insertion in a children's hospital. J Intraven Nurs. 1998;21:160-165.

13. Lininger R. Pediatric peripheral I.V insertion success rates. Pediatr Nurs. 2003;29:351-354.

14. Reigart JR, Chamberlain KH, Eldridge D, et al. Peripheral intravenous access in pediatric inpatients. Clin Pediatr (Phila). 2012;51:468-472. doi:10.1177/0009922811435164

15. Sebbane M, Claret PG, Lefebvre S, et al. Predicting peripheral venous access difficulty in the emergency department using body mass index and a clinical evaluation of venous accessibility. J Emerg Med. 2013;44:299-305. doi:10.1016/j.jemermed.2012.07. 051

\section{Dovepress}

\section{Publish your work in this journal}

Pediatric Health, Medicine and Therapeutics is an international, peerreviewed, open access journal publishing original research, reports, editorials, reviews and commentaries. All aspects of health maintenance, preventative measures and disease treatment interventions are addressed within the journal. Practitioners from all disciplines are

invited to submit their work as well as healthcare researchers and patient support groups. The manuscript management system is completely online and includes a very quick and fair peer-review system. Visit http://www.dovepress.com/testimonials.php to read real quotes from published authors. 